\title{
Sentimental Education
}

Grzegorz Grochowski 


\section{Commentaries}

Grzegorz Grochowski

\section{Sentimental Education}

DOI:10.18317/td.2018.en.1.14

$\mathbf{R}$ elations between literature and the world of emotions are undoubtedly numerous, complex, and ambiguous, and as such, difficult to frame with a simple and clear typology. One can, however, assume roughly that they resurface in three main areas and determine, to a degree, the work's genesis, content, and mode of interaction. Emotions play, therefore, three different roles: in the first instance they appear as the presumed, pre-textual and irrational source of artistic creation, a field of psychic tensions which provoke a person to reach for the pen. In the second case, various states of the heart are chosen as the object of presentation, becoming the topic of a moralizing or psychologizing deliberation, a phenomenon illustrated or evoked by a sequence of artistic images. Finally, in their third manifestation, they may be approached as an aspect of reading, as mechanisms influencing the nature of reception. The oldest literary tradition seems to rely on the third approach: already in Aristotle one finds the attempt to employ language in the service of the theory of reception, whose essence, as we all remember, lied in the experience of fear and pity. The genetic explanation, assuming the work to be a record of the author's emotional states, blossomed much later, mainly in the nineteenth century

\section{Grzegorz \\ Grochowski works \\ in the Institute \\ of Literary Studies at \\ the Polish Academy \\ of Sciences, doing \\ research in the fields \\ of poetics, genres, \\ and discourse. He is \\ the author of a book \\ on text hybrids \\ and co-author \\ of a dictionary \\ of cultural studies. He \\ is a member of the \\ editorial board of the \\ journal Teksty Drugie.}


and had several sources, including the romantic personalization of the poetic word, positivist determinism, and finally the spectacular development of psychology as a separate discipline which included also the psychology of creative processes, aspiring to the standard of science. This approach, undoubtedly, has been embodied best by psychoanalysis which explains literary images, tropes, and figures as phantasmal manifestations of the obsessive speech of desire. But one does not need to look as far as the Freudian theory of sublimation and secondary revision; a wish to decipher artistic images and use literature to enter the intimate world of the artist's emotions can be found also in several classical texts of twentieth-century philology and literary history. Juliusz Kleiner's monumental work repeatedly refers to emotions accompanying the artist writing certain passages, discusses the "atmosphere of renewed feelings which surrounded the composition of the poem," the presentation of "the results of experience" in the completed work, and asks about the extent to which the "emotional hue of the poet's memories" became more vivid in the process of writing. Although interpretations such as these are not based on any particular affect theory, the old fashioned trust in intuition and commonsensical assumptions endows them with a discreet retro charm.

Genetic interpretations and theories of reception are usually located, however, within the range of a broader concept and they bear a clear authorial mark, associated either with a particular scholar or a particular school of thought. Since the emotional life of neither the writer nor the reader is open to us, we must usually put our trust in the intuition of the scholar or the axioms of a given methodology while on the risky journey into the sphere of personal experiences and desires. What seems more tangible and recognizable (although some will view this as a superstition), is the dynamic of human emotions and states of the heart at the level of literary images, in the sphere of presented reality. A sphere which requires special attention because it is here that literature first determines and reveals its attitude to the world of emotions as well as its understanding of the phenomena of psychic life. It is also here that we see with the most clarity the role of the word in the shaping of the collective imagination through its symbolic potential, both mythologizing and demythologizing. Literary images of passion and emotion reveal the importance we assign to emotionality in our life, show where we locate its sources and how we perceive its role, betray the degree to which we identify with spontaneous emotions or wish to be separated from them, and outline the hierarchies we assign to them. Naturally, literature is not the only place where this takes place, nor does literature have a monopoly on the shaping of such convictions - it usually enters various relations, for instance, cooperating, competing with, or complementing other types of discourse (philosophical, religious, legal, scientific). Although, as Anthony Giddens claims 
in The Transformations of Intimacy, "modern societies have a covert emotional history, yet to be fully drawn into the open,"1 and the same can be said about the history of the collective emotional imagination, certain similarities are visible even at first glance.

French classical tragedy, for instance, constitutes an important chapter in the development of the literary anthropology of emotions (notably, in a discussion of the declaration of love included in this issue, the author refers precisely to Jean Racine's Phèdre) - departing from the ancient model determined by the categories of plot, catharsis, fate, and action it revaluates the notion of character, transforming drama into a study of passion. The work's structure is no longer dominated by the iron logic of events, aiming to present the human being as succumbing to affects and confronted with the moral principles, entangled in the conflict between duty and desire. It is hard to overlook the fact that the same cultural formation gave birth to Passions of the Soul, where Descartes attempts to catalogue, order, explain, and in fact cognitively tame the "movement of the spirits" in their various forms. The philosopher approached his task with the utmost meticulousness, venturing even into the areas of anatomical explanation and deciding that, contrary to the general belief, emotions are located not in the heart but in "the little gland in the middle of the brain whence it radiates into all the rest of the body by the mediation of spirits, nerves, even blood, which, participating in the impressions of the spirits, can carry them through the arteries into all the members."2 Such explanations have their undeniable charm, but what seems crucial here is the clear distrust of the soul's mysteries in this instrumental approach to human emotions - Descartes directly formulates the problem of their proper "use" and asks "wherein all the passions are serviceable and wherein they are harmful." ${ }^{3}$ Naturally, the artistic vision seems more pessimistic and mesmerized by the fatal power of passion while the discourse of rationalism clearly opts for the strategy of objectification. However, despite all their differences, there is a similarity in the impulse to submit passions to a detailed (poetic or philosophical) vivisection and, consequently, to enable their differentiation, evaluation, and control.

Actually, it would be more difficult to locate such aspirations two centuries later in Charles Darwin's classic The Expression of the Emotions in Man

1 Anthony Giddens, The Transformations of Intimacy. Sexuality, Love and Eroticism in Modern Societies (Stanford, CA: Stanford University Press, 1992), 2.

2 Rene Descartes, The Passions of the Soul, trans. Stephen Voss (Indianapolis: Hackett Publishing Company, 1989), 37.

3 Ibid., 59 . 
and Animals. The work does not deliberate on the measures to be employed against passion or reflect on the joys of the soul, but it retains the impulse for classification and systematic explanation. Darwin is interested mostly in the etiology and symptomatology of all affects, which is why his work presents, first and foremost, a detailed study of the somatic causes behind phenomena such as low spirits, tender feelings, sulkiness, ill temper, or horror (and while the work reveals no clear desire here to control the impulses of the heart, one may still sense in it a tone of cognitive superiority with regard to reactions that can be analyzed in comparison with the stamping of rabbits or the rattling of porcupines). The complications of emotional life are explained thus not by referencing some abstract spirits, but rather established behavioral habits - the swelling of the body, the pouting of lips, drawing back of the ears, frowning, or "contraction of the platysma myoides muscle."4 This focus on the anatomical mechanisms may have been caused by the progressive specialization of the various spheres of human cultural activity and the growing distance between particular discourses: scientific, philosophical, ethical, artistic, and religious. The elimination of the teleological aspects should be interpreted as an attempt to preserve cognitive objectivity and a sign of an increased methodological awareness leading to the removal of all external influences from the (say, psychological) deliberation. However, one could also argue that Darwin was an advocate not only of the unadorned truth of natural sciences but also of the attitudes found in the voluminous literary works of the era. After all, a similar reductionism became the official artistic ideology of Emil Zola who explains his famous tale of adultery and murder by referencing Taine's comparison of vice and virtue to chemical substances such as vitriol and sugar. As a matter of fact, the scientist, quasi-biological approach to the issue of emotions appeared in literature already a little earlier, in Balzac's The Human Comedy, a cycle which may be read as an almost encyclopedic compendium of all human passions - from ambition, through anxiety, envy, shame to despair and fear (the author's fascination with empiricism can be seen already in his method - usually a case study - and in the analytical approach signaled for instance by the "scientific" metaphor in the title of The Physiology of Marriage). And at the level of immanent poetics, one cannot overlook the popularity of physiognomy in nineteenth-century literature which used the characters' appearance as a medium to express their psychological construction. Naturally, we are talking here about certain imaginative clichés, typical phenomena which did not encompass the entire array of artistic creation from the era. However, the presence of the naturalistic context (even if

4 Charles Darwin, The Works of Charles Darwin, vol. 23, The Expression of the Emotions in Man and Animals (New York: NY University Press, 1989), 233. 
muted or minimal) can be found even in the great stories about the failing mechanism of emotional adaptation such as Madame Bovary or Anna Karenina.

The nineteenth-century fascination with anatomy and physiology of emotion culminated in the masterpiece of the following century where it also transformed into its direct opposite. I am talking, of course, about Proust's consecutive volumes where he penetrates the microstructure of emotion to such depths that it loses any recognizable, permanent shape, and changes its consistency, falling apart into a sequence of poorly coordinated tremors of sensitivity, returning resentments, and fleeting observations. The inhuman distance accompanying Proust on his journey through the labyrinth of time is admittedly typical of the entire era dawning at that moment. Twentieth-century literature has largely confirmed the diagnosis proposed by Ortega y Gasset in The Dehumanization of Art where "a work of art vanishes from sight for a beholder who seeks in it nothing but the moving fate of John and Mary or Tristan and Isolde."5 Indeed, the writers of the twentieth century, from Joyce to Beckett, from Gombrowicz to Białoszewski, generally used their work as a laboratory for new forms of speech, careful to avoid the issue of the dilemmas of the heart. The novel began to deconstruct existing conventions (through various travesties, parodies, and pastiches), problematize the properties of the material (in several types of linguistic prose), and ask questions about the essence of the creative act (in its intertextual varieties). Drama focused on presenting the alienating power of language and on documenting communicative paralysis (although one should add, perhaps, that several forms of this particular literary genre retained the strongest traces of the fascination with the drama of various emotional tensions.) Finally, poetry, associated not that long ago with eruptions of lyricism, became largely - to quote Ortega y Gasset yet again - a "higher algebra of metaphor." Admittedly, suggestive counter-examples could be evoked with reference to individual artists and their selected works. After all, it seems hardly possible to purge literature (and poetry in particular) entirely of the theme and the problem of emotions, and such a radical and finite separation of the word from the sphere of human experience would surely result in a great impoverishment. Thus, feelings do occasionally have a voice in the work of this or other more lyrically minded writer or poet of the era, but their presence, usually muted by the avant-garde shaming of emotions (notable also in the classical modes), is camouflaged, veiled, translated into a language of motor tensions, reduced to equivalent imagery or encoded

5 Jose Ortega y Gasset, The Dehumanization of Art and Other Essays on Art, Culture and Literature (Princeton: Princeton University Press, 1968), 10. 
in a sequence of metaphorical hieroglyphics (which happens in the works of authors as different as Bruno Schulz and Julian Przyboś).

This tendency undoubtedly goes beyond the sphere of artistic activity, which allows once again to look for similarities, analogies, and mutual influences between the various spheres of culture. For instance, the discourse of literary studies focused on binary oppositions, narrative patterns, layered configurations, generic systems, and conventional structures. All the while, the emotional reception of the work was classified - for instance by the New Critics - as an "affective fallacy." Even a casual observer must see clearly that mainstream philosophy of that period also shifted almost entirely toward language - it would be hard to find approaches treating emotions as a guarantee of reliable cognition or a source of legitimate sense. Music which, according to Ortega y Gasset from Beethoven to Wagner constituted an expression of personal feelings or even a melodrama, in the more recent period became an acoustic phenomenon, a precise combination of sounds, or a random cacophony, as a consequence of not only Debussy, but also Stravinsky, Stockhausen and Cage.

But the picture would be incomplete without mentioning, at least in passing, a significant fracture dividing twentieth-century culture into two areas governed by dramatically different, perhaps even contradictory principles. Programmatic antihumanism became, paradoxically, a battle cry of culture originating in humanism, celebrating cognitive or esthetic values, aspiring to sovereignty and, at least declaratively, striving to cast off ideological and market circumstances. At the same time, there emerged a separate world of popular texts seemingly aimed precisely at showing and provoking various emotions. In fact, one could probably create an emotional genealogy where individual units and genre varieties - melodrama, horror, soap opera, romantic comedy, crime story - are distinguished by the appropriate set of dominant emotions, experiences, moods, and sentiments. In fact, this kind of a mechanical association of form, genre, content, and stereotypes of reception, where literature becomes a kind of spiritual tickling, was precisely what made it anathema to several writers, critics, and thinkers representing both the aristocratic and the emancipatory visions of culture. However, as we know from Freud, all that which is repressed returns as a phantasm, disguised as something else, simultaneously evoking disgust as well as desire, rejected but continuously renewed. This is why the ghosts of simple, naive emotions, native usually to the land of kitsch, crossed from time to time the symbolic barrier and visited the world of sublimated art, disturbing the peace of the solipsistic aesthetes. Actually, several writers and artists summoned these specters themselves and - faced with the exhaustion of high art - reached for forms and methods typical of cabaret, pulp literature tabloid press, comics, 
and advertising (let us only mention S. I. Witkiewicz, W. Gombrowicz, A. Warhol, R. Lichtenstein, J. Cortazar, U. Eco). On the other hand, one can clearly see that by neighboring so-called "high art," popular culture has learned a lot and largely shed its simplistic aesthetic naiveté. Movie theatres today, apart from traditional comedies, horrors, and tear-jerkers, increasingly often present narratives which go beyond the simple model of "emotional contagion" by filtering emotions through the sieve of exaggerated stylization and play with generic conventions underpinned with ironic distance. Techniques of composition, methods of editing, and narrative strategies, once associated with great innovators, gradually have become commonplace in mass entertainment. Avant-garde techniques of image creation are used today even in purely persuasive forms such as commercials.

If we go back to literature for a diagnosis of its current state, we will see that writers more eagerly "pollute" their work with the "burden" of the human affects than they did in the mid-twentieth century. The majority of important novels from the last few decades (again, instead of an exhaustive presentation let me enumerate a handful of authors as different as Y. Andrukhovych, J. M. Coetzee, M. Cunningham, I. McEwan, S. Rushdie, S. Selenić, D. Ugresic, M. Vargas Llosa, S. Walters) center on seemingly banal, clichéd, and simple subjects such as infatuation, betrayal, departure, nostalgic yearning, pain, and loneliness. Contrary to their great predecessors, their authors rarely take up journeys leading potentially to the discovery of another form of metafiction, a presentation more radical than the stream of consciousness or to the creation of a novel whose elements can be rearranged in several different ways. Instead, they eagerly present emotional conflicts, yield to the temptation of lyricism, sometimes even reach for clearly sentimental plots. Notably, authorial preferences of this kind parallel the tendencies found today also in other areas of culture. For instance, linguistics - not that long ago still obsessed with systems, reaching for the mathematical methods and viewed as an ideal of exactness, precision, and methodological purism - today (mainly in its cognitive version) increasingly often analyzes phenomena as indeterminate as the experience of love or the ideal of happiness (see, for instance, Luhmann's Love as Passion or Anatomia szczęścia. Emocje pozytywne w jezzykach i kulturach świata [The Anatomy of Happiness: Positive Emotions in Languages and Cultures of the World] edited by A. Duszak and N. Pawlak). It is difficult to evaluate this tendency from the perspective of literary audiences. It has brought some undoubtedly beneficial results: the word, in a way, has acquired substantiality, has become saturated with real content (however we decide to interpret the latter), and it probably also resonates better with readers. This positive evaluation, however, is accompanied by a certain uneasiness. Despite their unquestionable value, a substantial number of recent works seems to be - to 
some extent - underpinned with sentimentalism accompanied by its usual faults including moral impatience, a tendency to generalize, a mythologization of happy intimate relationships, and the naive belief in the spontaneous goodness of the "common man." It is something more than simply a shameful disposition of the less notable writers. It is a shadow, however discreet and subtle, falling across the work of the most renowned and "brutal" contemporary authors, not to mention at least some of Michel Houellebecq's novels. And it is not true that the specter of sentimentality is not detrimental to those, indeed exquisite, works. Meanwhile, the authors of the truly intriguing texts use emotions as a tool for gaining cultural knowledge or as a means of social critique; they spin the narrative of feelings, but only to show, as Michel Faber does in his Victorian lampoon, their impossibility in a given world.

Translation: Anna Warso 